ScIDice

\section{International Journal of Dentistry and Oral Science (IJDOS) \\ ISSN: 2377-8075}

\title{
Complications In Implant Therapy: A Review
}

Review Article

Divya Rupawat ${ }^{1}$, Vinay Sivaswamy ${ }^{2 *}$

${ }^{1}$ Saveetha Dental College, Saveetha Institute of Medical and Technical Sciences, Saveetha University, Chennai- 600077, India.

${ }^{2}$ Associate Professor, Department of Prosthodontics, Saveetha Dental College, Saveetha Institute of Medical and Technical Sciences, Saveetha University - Chennai - 600077, India.

\section{Abstract}

The most common complications in implant dentistry occur after loading of an implant. There are many factors that need to be considered by the clinician while planning for an implant prosthesis. These include patient factors like bone density, ridge defects,systemic factor and implant related factors like implant angulation, type of loading of implant, type of occlusion given, implant component factors and others. A comprehensive search was initiated in PubMed Central, Medline, Cochrane, Embase, Ovid, Science Direct, Copernicus and Google Scholar databases for terms related to complications in dental implants. Systematic reviews, Randomised Controlled Trials, Prospective clinical studies, and Case control studies were included. Case reports, In vitro studies and studies involving animals were excluded from the search. Based on the analysis, implant complications were divided as biological complications and prosthetic complications. Prosthetic complications were further classified as mechanical and technical complications. Implants are more susceptible to biological complications which include Peri-Mucositis and Peri-implantitis. These are treated with curettage, laser therapy, antimicrobial therapy and bone regenerative techniques. The most common prosthetic complication is screw loosening occurring due to loss of preload, however, other complications like screw fracture, abutment fracture, veneer chipping and framework fracture are also observed to occur. Proper planning and awareness are required to prevent these complications and thereby increase the success of implant therapy.

\section{Introduction}

Edentulism is a condition in which there is partial or complete loss of teeth that can adversely affectaperson's appearance and functions such as mastication and phonation which ultimately affects the well being and quality of life [20]. The use of dental implants to replace natural teeth lost to trauma, dental caries, or periodontal disease has become a predictable form of prosthetic treatment and is gaining popularity since the early 1980 s [27]. These are usually endosseous implants placed in the residual jaw bone or after grafting procedures [3]. These procedures could present complications.

The placement of dental implants require precision, operator skill and are highly patient sensitive [5]. The osseointegration of a dental implant depends on bone remodelling process, patient metabolic factors as well as other systemic factors [22]. The complications in implant therapy may be due to poor planning, poor case selection, or even poor implementation of the treatment plan [23]. In addition once the surgical phase is over, the longevity is dictated by the restoration as the implant is loaded only after the restoration [26]. The implant is introduced to function in the oral cavity after the crown is placed on it and that is when it receives masticatory forces; this is when maximum complications could happen [15]. Natural tooth is surrounded by a periodontal ligament which acts as a shock absorber to harmful forces before distributing them to the bone whereas the implant bone connection is rigid and the forces are directly transferred to the bone [9]. The success rates for dental implants have been measured by the presence of osseointegration and lack of peri-implantitis [10]. Dental implants have high rates of long term survival ( $\geq 10$ years) when used to support various types of dental prostheses [30]. However, because functional implants and their restorations may be prone to mechanical and biological difficulties, long-term success of dental implants is not the same as survival [29]. A clear understanding of the complications of dental implants is prudent

\section{*Corresponding Author:}

Vinay Sivaswamy,

Associate Professor, Department of Prosthodontics, Saveetha Dental College, Saveetha Institute of Medical and Technical Sciences, Saveetha University - Chennai - 600077, India. Tel: 9176923110

Email ID: vinay.sdc@saveetha.com

Received: May 05, 2021

Accepted: June 20, 2021

Published: June 30, 2021

Citation: Divya Rupawat, Vinay Sivaswamy. Complications In Implant Therapy: A Review. Int J Dentistry Oral Sci. 2021;08(5):2913-2917.

doi: http://dx.doi.org/10.19070/2377-8075-21000571

Copyright: Vinay Sivaswamy ${ }^{\circ} 2021$. This is an open-access article distributed under the terms of the Creative Commons Attribution License, which permits unrestricted use, distribution and reproduction in any medium, provided the original author and source are credited. 
as they are becoming more popular due to increased patient demand for fixed prosthesis. Therefore, the aim of this review is to present an overview on the causes of various types of complications related to implant therapy and to provide the practitioner with clinical concepts on their prevention and management.

\section{Materials And Methods}

Search databases: A comprehensive search was initiated in PubMed Central, Medline, Cochrane, Embase, Ovid, Science Direct, Copernicus and Google Scholar databases for terms related to complications in dental implants. Manual search for relevant articles were done in the Journal of Prosthetic Dentistry, Journal of Prosthodontics and Clinical Oral Implants and related Research to supplement the electronic search. No limitations regarding publication type and publication date were set.

Inclusion and Exclusion criteria: Systematic reviews, Randomised Controlled Trials, Prospective clinical studies, and Case control studies were included. Case reports, In vitro studies and studies involving animals were excluded from the search.

Search strategy: Article search and analysis was performed according to the guidelines and the principles of an integrative review. The keywords used were screw retained prosthesis, cement retained prosthesis, biological complications, mechanical complications as the objective of this review was to compileall complications related to dental implants.

\section{Results And Discussion}

Out of the 109 articles obtained from searching all databases, 75 studies were excluded based on title and abstract. Out of the remaining 34 studies, 18 were excluded based on the inclusion and exclusion criteria and 16 studies were included on the basis of their core data.

Depending on the data collected Implant Complications can be divided as follows:

\section{Biological Complications}

2. Prosthetic Complications

A. Mechanical Complications - related to complications of prefabricated or industrialcomponents.

B. Technical Complications - related to complications of laboratory-fabricated prostheses and/or their materials.

\section{Biological Complications}

Biological complications associated with dental implants are primarily inflammatory conditions of the soft tissues and bone surrounding implants and their restorative components [4]. These are induced by the accumulation of plaque and bacterial biofilm. Such conditions have been named peri-implant mucositis and peri-implantitis, and need to be differentiated so that the clinician may assign a proper diagnosis and select a proper treatment modality in cases where disease is present [36]. The prevalence of peri-implantitis is estimated to be $4-15 \%$ among the surviving implant population (i.e., implants still in the mouth) [25]. The progression of this soft tissue inflammation leads to progressive bone loss.

The new classification for peri implant diseases and conditions $[6$, 43] is described below:

1. Peri-implant health: Clinically, peri-implant health is characterized by an absence of visual signs of inflammation and bleeding on probing [1].

2. Peri-implant mucositis: The main clinical characteristic of peri-implant mucositis is bleeding on gentle probing. Erythema, swelling, and/or suppuration may also be present. An increase in probing depth is often observed in the presence of peri-implant mucositis due to swelling or decrease in probing resistance. While there is strong evidence that peri-implant mucositis is caused by plaque, there is extremely limited evidence for non-plaque induced peri-implant mucositis. There is strong evidence from animal and human experimental studies that plaque is the etiological factor for peri-implant mucositis [14].

3. Peri-implantitis: Peri-implantitis was defined as a plaque-associated pathologic condition occurring in the tissue around dental implants, characterized by inflammation in the peri-implant mucosa and subsequent progressive loss of supporting bone. Periimplant mucositis is assumed to precede peri-implantitis. Periimplantitis is usually present in patients with a history of severe periodontitis due to poor plaque control [41].

4. Hard and soft tissue implant site deficiencies: Normal healing following tooth loss leads to diminished dimensions of the alveolar process/ridge that result in both hard and soft tissue deficiencies. Larger ridge deficiencies can occur at sites associated with severe loss of periodontal support, extraction trauma, endodontic infections, root fractures, thin buccal bone plates, poor tooth position, injury and pneumatization of the maxillary sinuses. Other variables that alter the ridge include drugs and systemic disorders that reduce the amount of naturally generated bone, tooth agenesis, and prosthetic pressure [13].

Majority of the implants used presently are platform switched as this shifts the implant abutment junction towards the centre of the fixture thus creating a microbial seal. The platform switched connections seemed to reduce the crestal bone loss which was corroborated in previous systematic reviews [50, 51]. However, with improved surface treatments and presence of microthreads there appears to be no significant difference in the bone loss in the platform matched and platform switched implants [33]. Bone level implants seem to have greater biological complications as compared to tissue level implants as the microgap between the implant and abutment is matched at bone level in the bone level implants [7]. In addition, the junction being at the tissue level for the latter gives space for soft tissue integration, this is not the case with bone level implants [7]. Maximum bone loss occurs up to first year after implant placement $[2,32]$. In most cases up to first year the loss is usually up to first thread. Bone is weakest to angled or shear forces and the strongest to compressive forces [18]. According to a systematic review rough threaded implant platforms may be helpful in maintaining the amount of marginal bone around implants as compared to machined smooth neck implants [55]. Meta-analysis showed that micro-threaddesign in the implant neck can reduce the amount of Marginal bone loss as compared to implants without microthreads [32]. When micro- 
threads are present at the crestal level the forces are transmitted in a mild yet steady manner and perpendicular to bone. This inturn helps in bone remodelling and preserving the crestal bone [16].

Treatment strategies: Peri-implant mucositis can be reversed with measures aimed at eliminating the plaque [21]. Peri-implantitis and other biological complications can be treated with nonsurgical or surgical approaches. They include nonsurgical mechanical debridement, local antimicrobial delivery in periodontitis and peri-implantitis with the help of tetracycline or doxycycline chips, and surgical debridement with bone grafting [24]. The implant has to be removed if more than $60 \%$ of bone is lost or if there is evidence of mobility [39, 24]. Mechanical debridement can be done with titanium curettes, however they have a chance of changing the surface microtopography of the implant [48]. Laser treatment has proven to be effective to treat peri-implantitis [31]. According to recent research Chitosan (a polymer) coated brushes do not affect the surface of implant and have shown good results in the treatment of peri-implantitis [49].

\section{Prosthetic Complications}

Mechanical Complications: These are related to problems arising withprefabricated or industrial components. They frequently occur due to biomechanical overloading when the implant position has a horizontal or an apical offset or when crowns are not given in occlusal harmony with the opposing teeth.

Screw loosening - This is one of the most common mechanical complications $[4,19]$. A certain amount of preload is given to the screw during the final cementation of an implant prosthesis by torquing it. The screw elongates at microscopic level, and this provides the tensile force required for preload application. Over a period of time due to masticatory forces, the metal surface of the screw gets worn and consequently there is loss of preload. The screw finally gives way when it has exceeded $75 \%$ of its ultimate tensile limit. The question that arises is "Is screw loosening a success or failure in implant therapy?”. In Implant Dentistry,Screw loosening is considered a regular norm as compared to other therapies. Internal connections have a higher preload value than that of the external hexagon design [44]. The conical configuration can spread the load along the fixture and the surrounding bone more homogeneously than both the external hexagon and traditional internal connections [34]. According to a systematic review, a 5 -year complication rate of $10.1 \%$ for internal connection and $12.4 \%$ for external connection [35]. Normally, such a complication can be addressed by tightening and torquing the screw in case of loosening. However, it is a remedial measure and repeated tightening simply induces more chances of screw loosening over a prolonged routine usage.

Screw fracture - Screw is the weakest part of the implant prosthetic components and likely to fracture first on unwanted forces [54]. In most finite element analysis studies, the factor of safety is lowered below 1 in the screw alone. Most of the time screw fracture occurs in cases having a non-passive framework. The micro gap between platform and framework results in flexure of the screw (contraction) every time the patient bites and may cause the screw to [42].

The methods proposed to remove a fractured screw include a dental instrument (explorer, hand scaler, ultrasonic scalers) ro- tated counter-clockwise, drilling a horizontal groove cut into the screw head has been advocated to engage the instrument with a flat-head driver or instrument, screw-retrieval kits are also available. Drilling must be done carefully to avoid damaging the internal bore threads.

Abutment fracture - This complication usually occurs in angulated implants or in cases with increased vertical cantilever [17]. When non-parallel implants are subject to occlusal loads there are shear or lateral forces acting on them that may cause fracture of the abutment. This is also the case when abutments over tilted implants are excessively milled in an attempt to make them parallel, the abutments become thin and subsequently have an increased chance of fracture. Ceramic abutments, both internally and externally connected, demonstrated a significantly higher incidence of abutment fractures than metal abutments [35].

Implant fracture: Fracture of implants is a terminal failure for implant therapy. It is associated with several factors, including material, implant diameter and length, presence of a cantilever, and bruxism, fit ,narrow implants, bone density [12]. Occlusion and cantilevers are considered important risk factors in the outcome of the implant restoration.Bruxism may significantly reduce implant survival $[12,8]$.

Technical Complications: These complications are related to complications of laboratoryfabricated prostheses and/or their materials. The frequency of occurrences of technical complications is greater in implant-supported FPDs as compared to the implant-supported removable prosthesis.

\section{Fracture of veneering porcelain}

There is an increased risk of this complication occurring in cases with excess horizontal or vertical cantilevers. An incidence of $3.4 \%$ for the fracture of the veneer ceramic and metal- ceramic restorations after 5 years was reported in a review [37]. The incidence of complication in posterior implant was $3.1 \%$ whereas it was only $1.7 \%$ in anterior implants [46]. This could be because there are increased masticatory forces in the posterior regions as compared to anterior region. The incidence of veneering material fracture increases to $12.4 \%$ in multiunit fixed implant-supported prostheses after 5 years $[51,52]$. This complication can be reduced by following the principles of implant protected occlusion [28].

\section{Fracture of the framework}

Implant prosthesis has to be given in such a way that it does not jeopardize the endurance limit of the prosthesis. This is possible if the fit of the prosthesis is passive. A misfit of the prosthesis produces additional strains on the framework which are time and again acting during mastication which could lead to fracture of the prosthesis [38]. When there is less inter-arch space in partially edentulous jaws, the implant-abutment interface and abutment retention screw are exposed to higher lateral bending loads, tipping, and elongation forces the risk of framework fracture is more. To correct the gross misfit of the abutment-superstructure relationship, cutting the framework or bar and then joining the sections by welding or soldering is recommended, but both techniques may further impair the original fit Refined approaches withpreciselaboratory procedures are still a requisite to achieve a passive fit with an implant-supported superstructure. Cement-re- 
tained implant-supported single crowns had a greater rate of biological issues, whereas screw-retained crowns had a greater rate of technical difficulties and screw loosening [47]. The introduction of CAD/CAM frameworks has enhanced both the design and production of prosthetics [45]. The enhanced fit of these frameworks eliminates the need for soldering or laser welding, which would have resulted in fracture-prone areas [40].

\section{Conclusion}

Implant therapy does not stop after delivery of the implant prosthesis. It is the duty of the clinician to consider all the possible complications that might occur. This article is corroborated by clinical evidence and gives an overview of possible implant complications. Biologic complications such as peri-implantitis or technical complication such as screw loosening may be expected and prevented with awareness on their etiologic factors.

\section{References}

[1]. Araujo MG, Lindhe J. Peri-implant health. J. Periodontol. 2018 Jun;89: S230-S236

[2]. Atieh MA, Zadeh H, Stanford CM, Cooper LF. Survival of short dental implants for treatment of posterior partial edentulism: a systematic review. Int J Oral Maxillofac Implants. 2012 Dec 1;27(6):1323-1331.

[3]. Barone A, Ricci M, Calvo-Guirado JL, Covani U. Retracted: bone remodelling after regenerative procedures around implants placed in fresh extraction sockets: an experimental study in Beagle dogs. Clin. Oral Implants Res. 2011 Oct;22(10):1131-7.

[4]. Berglundh T, Persson L, Klinge B. A systematic review of the incidence of biological and technical complications in implant dentistry reported in prospective longitudinal studies of at least 5 years. J Clin Periodontol. 2002;29 Suppl 3:197-212.Pubmed PMID: 12787220.

[5]. Brignardello-Petersen R. Single anterior maxillary dental implants have good esthetic and patient satisfaction outcomes 3 years after placement. J. Am. Dent. Assoc.. 2017 Apr 1;148(4):e27.

[6]. Caton JG, Armitage G, Berglundh T, Chapple IL, Jepsen S, Kornman KS, et al. A new classification scheme for periodontal and peri-implant diseases and conditions-Introduction and key changes from the 1999 classification. J. Periodontol. 89 Suppl 1, pp. S1-S8.

[7]. Chiapasco M, Casentini P, Zaniboni M. Implants in reconstructed bone: a comparative study on the outcome of Straumann ${ }^{\circ}$ tissue level and bone level implants placed in vertically deficient alveolar ridges treated by means of autogenous onlay bone grafts. Clin Implant Dent Relat Res. 2014 Feb;16(1):32-50.Pubmed PMID: 22494433.

[8]. Chrcanovic BR, Kisch J, Albrektsson T, Wennerberg A. Factors influencing the fracture of dental implants. Clin Implant Dent Relat Res. 2018 Feb;20(1):58-67.

[9]. Karimi Dastgerdi A, Rouhi G, Dehghan MM, Farzad-Mohajeri S, Barikani HR. Linear Momenta Transferred to the Dental Implant-Bone and Natural Tooth-PDL-Bone Constructs Under Impact Loading: A Comparative in-vitro and in-silico Study. Front Bioeng Biotechnol. 2020 Jun 12;8:544. Pubmed PMID: 32596223.

[10]. Degirmenci K, Atala MH. The impact of different dental implant surface properties to osseointegration success of dental implants-A systematic review. Clin. Oral Implants Res. 2019 Sep;30:280.

[11]. 'Fracture resistance of cement, screw and cement and screw retained metalceramic implant restorations' (2017) Clinical Oral Implants Research, pp. 103-103. doi: 10.1111/clr.102_13042.

[12]. Green NT, Machtei EE, Horwitz J, Peled M. Fracture of dental implants: literature review and report of a case. Implant Dent. 2002 Jun 1;11(2):13743.

[13]. Hämmerle CH, Tarnow D. The etiology of hard-and soft-tissue deficiencies at dental implants: A narrative review. J. Clin. Periodontol. 2018 Jun;45:S267-77.

[14]. Heitz-Mayfield LJ, Salvi GE. Peri-implant mucositis. J. Clin. Periodontol. 2018 Jun; 45:S237-45.

[15]. Hobkirk JA, Brouziotou-Davas E. The influence of occlusal scheme on masticatory forces using implant stabilized bridges. J Oral Rehabil. 1996 Jun;23(6):386-91.Pubmed PMID: 8809692.

[16]. Huja SS. Microhardness, strains and microdamage in bone surrounding en- dosseous implants subjected to bending-fatigue loads. Indiana University; 1999.

[17]. Jalalian E, Yousofi Z. Comparing Torque Loss in Standard Implants and Short Implants with Increased Vertical Cantilever Abutments: an In Vitro Study. Braz. Dent. Sci. 2021;24(1):8.

[18]. Javed F, Romanos GE. Role of implant diameter on long-term survival of dental implants placed in posterior maxilla: a systematic review. Clin Oral Investig. 2015 Jan;19(1):1-10.Pubmed PMID: 25366871.

[19]. Jung RE, Zembic A, Pjetursson BE, Zwahlen M, Thoma DS. Systematic review of the survival rate and the incidence of biological, technical, and aesthetic complications of single crowns on implants reported in longitudinal studies with a mean follow-up of 5 years. Clin Oral Implants Res. 2012 Oct;23 Suppl 6:2-21.Pubmed PMID: 23062124.

[20]. Khan SU, Ghani F, Nazir Z. The effect of some missing teeth on a subjects' oral health related quality of life. PaK J Med Sci. 2018 Nov;34(6):14571462.

[21]. Koutouzis T. Implant-abutment connection as contributing factor to periimplant diseases. Periodontol 2000. 2019 Oct;81(1):152-166.Pubmed PMID: 31407436.

[22]. Krisam J, Ott L, Schmitz S, Klotz AL, Seyidaliyeva A, Rammelsberg P, et al. Factors affecting the early failure of implants placed in a dental practice with a specialization in implantology - a retrospective study. BMC Oral Health. 2019 Sep 5;19(1):208.Pubmed PMID: 31488110.

[23]. Kulakov AA, Kasparov AS, Porfenchuk DA. Factors affecting osteointegration and the use of early functional load to reduce the duration of treatment in dental implantation. Stomatologiia. 2019 Jan 1;98(4):107-15.

[24]. Labban N, Shibani NA, Al-Kattan R, Alfouzan AF, Binrayes A, Assery MK. Clinical, bacterial, and inflammatory outcomes of indocyanine green-mediated photodynamic therapy for treating periimplantitis among diabetic patients: a randomized controlled clinical trial. Photodiagnosis Photodyn Ther. 2021 May 22:102350.Pubmed PMID: 34033934.

[25]. Labh AK, Bennis MA, Mani G. Prevalence of Peri-Implantitis and Peri-Implant Mucositis among Implant Patients: A Dental University Based Study. J Long Term Eff Med Implants. 2021;31(1): 59-64.

[26]. Malchiodi L, Balzani L, Cucchi A, Ghensi P, Nocini PF. Primary and Secondary Stability of Implants in Postextraction and Healed Sites: A Randomized Controlled Clinical Trial. Int J Oral Maxillofac Implants. 2016 Nov/Dec;31(6):1435-1443.Pubmed PMID: 27861670.

[27]. Meredith N. The role of implants in restorative dentistry. 1: The replacement of missing teeth. Dental update. 1997 May 1;24(4):159-63.

[28]. Misch, C. E. Dental Implant Prosthetics - E-Book. Elsevier Health Sciences.2014.

[29]. Morton D, Gallucci G, Lin WS, Pjetursson B, Polido W, Roehling S, et al. Group 2 ITI consensus report: prosthodontics and implant dentistry. Clin. Oral Implants Res. 2018 Oct;29(Suppl 16):215-23.

[30]. Muddugangadhar BC, Amarnath GS, Sonika R, Chheda PS, Garg A. Metaanalysis of Failure and Survival Rate of Implant-supported Single Crowns, Fixed Partial Denture, and Implant Tooth-supported Prostheses. J Int Oral Health. 2015 Sep;7(9):11-7.Pubmed PMID: 26435609.

[31]. Nevins M, Nevins ML, Yamamoto A, Yoshino T, Ono Y, Wang CW, et al. Use of Er: YAG laser to decontaminate infected dental implant surface in preparation for reestablishment of bone-to-implant contact. Int J Periodontics Restorative Dent. 2014 Jul 1;34(4):461-466.

[32]. Niu W, Wang P, Zhu S, Liu Z, Ji P. Marginal bone loss around dental implants with and without microthreads in the neck: A systematic review and meta-analysis. J Prosthet Dent. 2017 Jan;117(1):34-40.Pubmed PMID: 27646798.

[33]. Parsikia F, Amini P, Asgari S. Influence of mechanical and chemical surface treatments on the formation of bone-like structure in $\mathrm{cpTi}$ for endosseous dental implants. Appl. Surf. Sci. 2012 Oct 15;259:283-7.

[34]. Pesce P, Menini M, Bagnasco F, Mussano F, Pera F, Carossa M. Internal and external hexagon connections in immediately loaded implants full-arch rehabilitations. Clin. Oral Implants Res. 2018 Oct;29:206.

[35]. Pjetursson BE, Zarauz C, Strasding M, Sailer I, Zwahlen M, Zembic A. A systematic review of the influence of the implant-abutment connection on the clinical outcomes of ceramic and metal implant abutments supporting fixed implant reconstructions. Clin Oral Implants Res. 2018 Oct;29 Suppl 18:160-183.Pubmed PMID: 30306682.

[36]. Romanos GE, Delgado-Ruiz R, Sculean A. Concepts for prevention of complications in implant therapy. Periodontology 2000. 2019 Oct;81(1):7-17.

[37]. Sadid-Zadeh R, Kutkut A, Kim H. Prosthetic failure in implant dentistry. dent. clin. 2015 Jan 1;59(1):195-214.

[38]. Sailer I, Mühlemann S, Zwahlen M, Hämmerle CH, Schneider D. Cemented and screw-retained implant reconstructions: a systematic review of the survival and complication rates. Clin. Oral Implants Res. 2012 Oct;23:163201.

[39]. Saleh, F. (no date) 'Regenerative treatment of peri-implantitis'. doi: 
10.26226/morressier.5ac3832d2afeeb00097a3db9.

[40]. Schilli, W. Current Trends in Implant Dentistry. Implant Dent.1996:53 .

[41]. Schwarz F, Derks J, Monje A, Wang HL. Peri-implantitis. J. Clin. Periodontol. 2018 Jun; 45:S246-66.

[42]. Teichmann M, Göckler F, Weber V, Yildirim M, Wolfart S, Edelhoff D. Ten-year survival and complication rates of lithium-disilicate (Empress 2) tooth-supported crowns, implant-supported crowns, and fixed dental prostheses. J Dent. 2017 Jan;56:65-77.Pubmed PMID: 27984088.

[43]. Tonetti MS, Greenwell H, Kornman KS. Staging and grading of periodontitis: Framework and proposal of a new classification and case definition. J. Periodontol. 2018 Jun;89:S159-72.

[44]. 'Torque maintenance and fracture resistance of UCLA abutment retaining screws whit different insertion torques in morse taper and external hexagon connections' (2017) Clinical Oral Implants Research, pp. 93-93. doi: $10.1111 /$ clr.92_13042.

[45]. Turkyilmaz, I. (2015) CAD/CAM Technology in Implant Dentistry.

[46]. Vigolo P, Givani A, Majzoub Z, Cordioli G. A 4-year prospective study to assess peri-implant hard and soft tissues adjacent to titanium versus goldalloy abutments in cemented single implant crowns. J Prosthodont. 2006 Jul-Aug;15(4):250-6.Pubmed PMID: 16827738.

[47]. Violeta, M. C. and Violeta, V. M. C. (no date) 'Fracture resistance of cement, screw and cement and screw retained metalceramic implant restorations'. doi: 10.26226/morressier.59492152d462b80296c9f143.

[48]. Wagner TP, Pires PR, Rios FS, de Oliveira JAP, Costa RDSA, Cunha KF, et al. Surgical and non-surgical debridement for the treatment of peri-implantitis: a two-center 12-month randomized trial. Clin Oral Investig. $2021 \mathrm{Mar}$ 16.Pubmed PMID: 33725166
[49]. Walczak K, Thiele J, Geisler D, Boening K, Wieckiewicz M. Effect of Chemical Disinfection on Chitosan Coated PMMA and PETG Surfaces-An In Vitro Study. Polymers (Basel). 2018 May 16;10(5):536.Pubmed PMID: 30966570 .

[50]. Chrcanovic BR, Albrektsson T, Wennerberg A. Platform switch and dental implants: A meta-analysis. J. Dent. 2015 Jun 1;43(6):629-46.

[51]. Atieh MA, Ibrahim HM, Atieh AH. Platform switching for marginal bone preservation around dental implants: a systematic review and meta-analysis. J. Periodontol. 2010 Oct;81(10):1350-66.

[52]. Wennström J, Zurdo J, Karlsson S, Ekestubbe A, Gröndahl K, Lindhe J. Bone level change at implant-supported fixed partial dentures with and without cantilever extension after 5 years in function. J. Clin. Periodontol. 2004 Dec;31(12):1077-83.

[53]. Wennström JL, Ekestubbe A, Gröndahl K, Karlsson S, Lindhe J. Oral rehabilitation with implant-supported fixed partial dentures in periodontitissusceptible subjects. A 5-year prospective study. J Clin Periodontol. 2004 Sep;31(9):713-24.Pubmed PMID: 15312092.

[54]. Wittneben JG, Buser D, Salvi GE, Bürgin W, Hicklin S, Brägger U. Complication and failure rates with implant-supported fixed dental prostheses and single crowns: a 10-year retrospective study. Clin Implant Dent Relat Res. 2014 Jun;16(3):356-64.

[55]. Zhang Q, Yue X. Marginal Bone Loss around Machined Smooth Neck Implants Compared to Rough Threaded Neck Implants: A Systematic Review and Meta-Analysis. J Prosthodont. 2021 Jun;30(5):401-411.Pubmed PMID: 33462909. 